
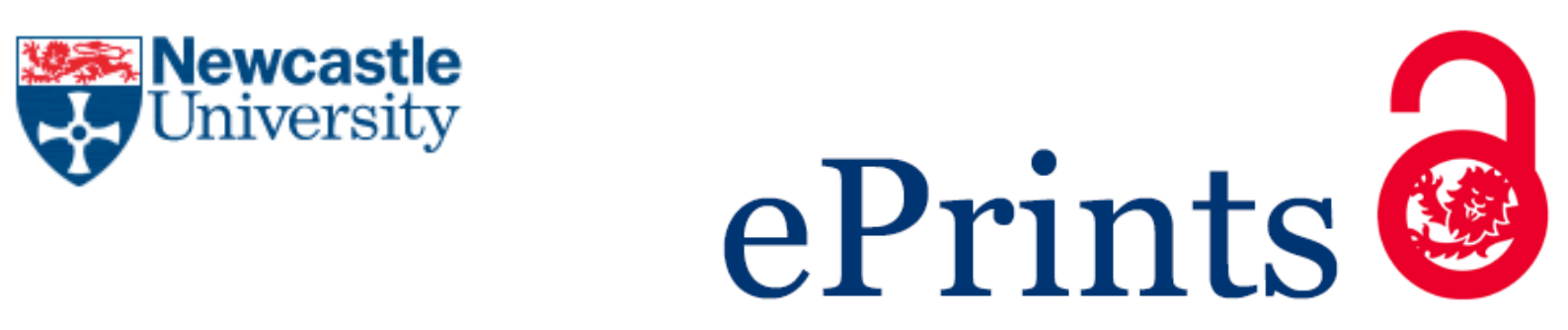

Wigham S, Barton S, Parr JR, Rodgers J.

A systematic review of the rates of depression in children and adults with

high functioning autism spectrum disorder.

Journal of Mental Health Research in Intellectual Disabilities 2017, 10(4), 267287.

\title{
Copyright:
}

This is an Accepted Manuscript of an article published by Taylor \& Francis in Journal of Mental Health in Intellectual Disabilities on 22/03/2017, available online:

https://doi.org/10.1080/19315864.2017.1299267

DOI link to article:

https://doi.org/10.1080/19315864.2017.1299267

Date deposited:

$21 / 03 / 2017$

Embargo release date:

22 March 2018

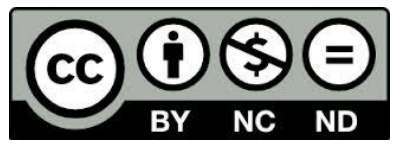

This work is licensed under a

Creative Commons Attribution-NonCommercial-NoDerivatives 4.0 International licence 

5 6 (7)

\section{A systematic review of the rates of depression in children and adults with high} functioning autism spectrum disorder
Abstract
Accurate population rates of depression can inform allocation of health resources and service planning, to counter the impact of depression on quality of life and morbidity. A systematic review of the rates of depression in children and adults with ASD and without intellectual disability (HF ASD) was conducted. Nineteen studies met inclusion criteria. Reported rates of depression varied; the reasons for this are discussed including availability of psychometrically valid and reliable measures of depression for people with HF ASD, and heterogeneity of study design. Further examination of the phenomenology of depression in HF ASD linked to the development of psychometrically valid assessment measures would facilitate epidemiological studies, improve clinical case recognition and inform treatments and interventions.

Keywords: depression, autism, HF ASD, systematic review, children, adults, public health 


\section{Introduction}

Depression is a potential co-existing condition in people with autism spectrum disorder (ASD). Some evidence suggests depression may be a secondary consequence of the social communication difficulties of people with HF ASD, who may experience increased risk of bullying, and pressures to conform to societal 'norms' (APA, 2013; Kelly, Garnett, Attwood \& Peterson, 2008; Whitehouse, Durkin, Jaquet \& Ziatas, 2009). Accurate population rates of depression are important for guiding resource allocation and service development, to minimize negative effects on quality of life and daily living activities, and reduce the risk of suicide (Johansson, Carlbring, Heedman, Paxling, \& Andersson, 2013; Stewart, Barnard, Pearson, Hasan \& O’Brien, 2006; Williams, O’Conner, Eder \& Whitlock, 2009;). However, accurate epidemiological evidence of rates of depression in people with ASD relative to the general population is lacking, and to date there are no population wide studies of prevalence of depression in HF ASD (De la Iglesia \& Olivar, 2015; Stewart et al., 2006).

In the United States, the general population prevalence of major depressive disorder during a 12 month period was $6.7 \%$ of adults $(n=9282)$, and $10.7 \%$ of children (Kessler, Chiu, Demler \& Walters, 2005; US Department of Health, NSDUH, 2013). Current rates of depression in the UK were $3.7 \%$ of women and $2.5 \%$ of men $(n=6815)$ (Spiers et al., 2012). Comparable large scale surveys have not been undertaken with individuals with ASD. Previous reviews have focused on depression occurrence, presentation, treatment, measurement, risk factors and psychiatric comorbidity in ASD (De la Iglesia \& Olivar, 2015; Gillberg \& Billstedt, 2000; Mannion \& Leader, 2013; Tsai, 2014; Matson \& Nebel-Schwalm, 2007; Mazzone, Ruta \& Reale, 2012; Shtayermman, 2008; Skokauskas \& Gallagher, 2009; Stewart et al., 2006). Previously reported rates of depression have been inconsistent and this may be due to a number of factors. For example, depression has been suggested to be higher in individuals with ASD without intellectual disability (HF ASD) (Mazurek \& Kanne, 2010; 
Sterling, Dawson, Estes \& Greenson, 2008). However, this may be a methodological artefact or due to diagnostic overshadowing. For example, depression may manifest more behaviourally in people with intellectual disability (ID) (Hermans \& Evenhuis, 2010; Magnuson \& Constantino, 2011).

This review aimed to examine rates of depression in individuals with ASD without ID (HF ASD). IQ potentially confounds rates of depression, and may contribute to a different phenomenology in people with ID. Therefore a separate systematic review is needed to inform clinicians about depression in people with ASD and ID (Magnusen \& Constantino, 2011). This review therefore included the following steps:

1. Identification of depression rates in previous studies including adults with HF ASD 2. Assessment of study quality

3. In the context of 1 and 2, make recommendations about future research directions.

\section{Methods}

The review was undertaken and results presented in accordance with Preferred Reporting Items for Systematic Reviews and Meta Analyses guidelines, and registered with PROSPERO (registration CRD 42014014340).

\section{Inclusion and exclusion criteria}

Published articles reporting empirical research and printed in English, were included if they met the inclusion criteria; resources did not permit translation of articles in other languages. The inclusion and exclusion criteria are presented in Table 1. Where studies included people with IQs $>70$ and $\leq 70$, and the data was not presented separately, these were excluded unless at least $85 \%$ of participants had average range IQ. Studies reporting current rates of major depressive disorder (MDD) were included in the review. Studies reporting clinical or severe depression were included in the review if scaled scores used were specified as a numerical value. Studies on subclinical depression, dysthymia and lifetime 
rates of MDD were not included, facilitating meaningful comparison with general population prevalence rates of depression. Studies were only included if they used a measure of depression, a generic measure with a depression subscale, or assessed depression according to DSM/ICD criteria. For example, studies were excluded if they used the Child Behaviour Checklist (CBCL), which has anxious/ depressed and withdrawn/ depressed subscales, plus has some limitations in specificity for case recognition (Gjevik, Sandstad, Andreassen, Myhre \& Sponheim, 2015). No age restrictions were imposed.

Table 1 around here

\section{Information sources}

The following electronic databases were searched: MEDLINE, EMBASE, Cinahl, ERIC and PsycINFO. The reference lists of selected articles identified in the search were checked for further publications. Searches were carried out in September 2015, and limited to those published since 1992 when the term Asperger syndrome was defined by WHO; this review therefore covers the periods of DSM-IV and 5, ICD-9 and 10.

The search terms used in the titles field were: autis*; asperger*; depress*; comorbid*; mood; psych*.

\section{Study selection}

Screening of articles identified in the electronic searches was titles and abstracts, then full text and completed by SW. Where inclusion was uncertain, the team discussed the article and reached consensus.

\section{Data extraction}

Data were recorded in an extraction form and included: author, country, population, number of participants, age, depression measure used, IQ, study outcomes and study findings.

\section{Risk of bias}


93

94

95

96

97

98

99

100

101

102

103

104

105

Within study bias was assessed using criteria adapted from validated tools (Hoy et al., 2012; Munn, Moola, Riitano \& Lisy, 2014) (see Table 2), with the aim of highlighting characteristics with the potential to over or underestimate depression rates (Higgins \& Green, 2011). Bias was assessed independently by a second reviewer on $20 \%$ of the papers to check coding reliability; agreement was 79\%. Coding for the measurement of bias was discussed with the wider team, and consensus was reached.

\section{Table 2 around here}

\section{Results}

Nineteen studies met the inclusion criteria (Figure 1); data extracted on the characteristics of studies are shown in Table 3. No articles were excluded on grounds of bias. Given the considerable heterogeneity in study methodology, it was concluded that articles could not realistically be combined for a meta-analysis to show pooled rates of depression, therefore a narrative synthesis was used (The Joanna Briggs Institute, 2014). 
Figure 1. Summary of the search selection process

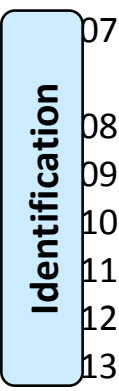

114

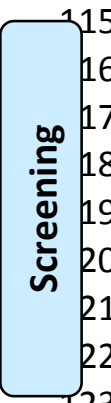

124

125

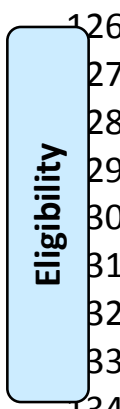

135

136

137

138

139

140

141

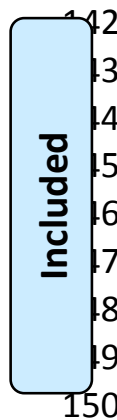

151

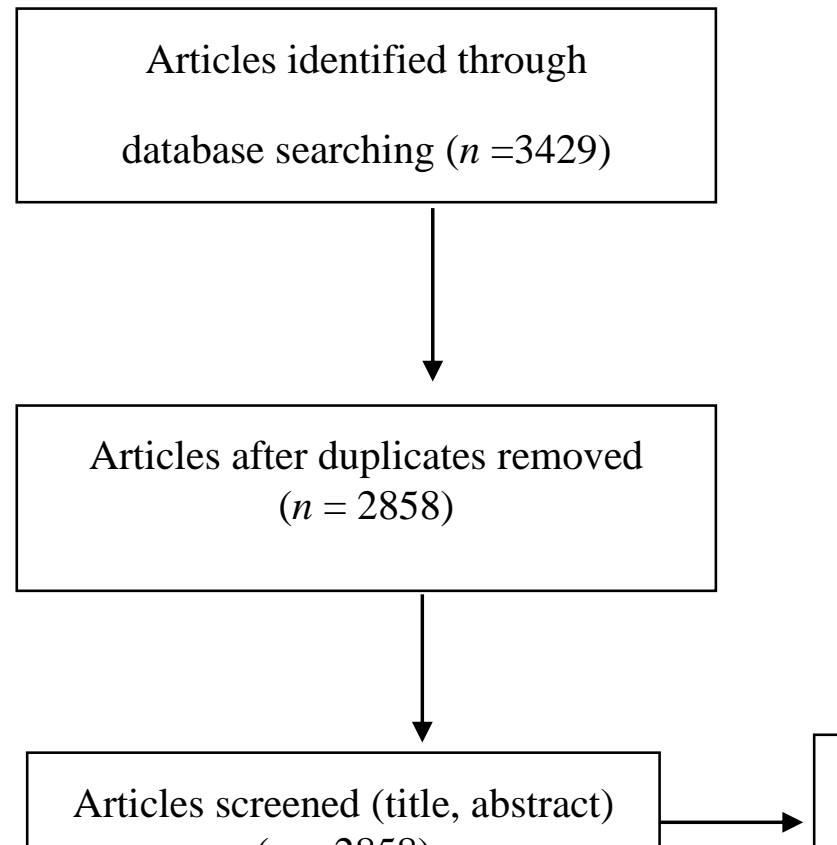

Articles excluded by screening title/abstract $(n=2537)$
Additional articles identified through other sources $(n=3)$

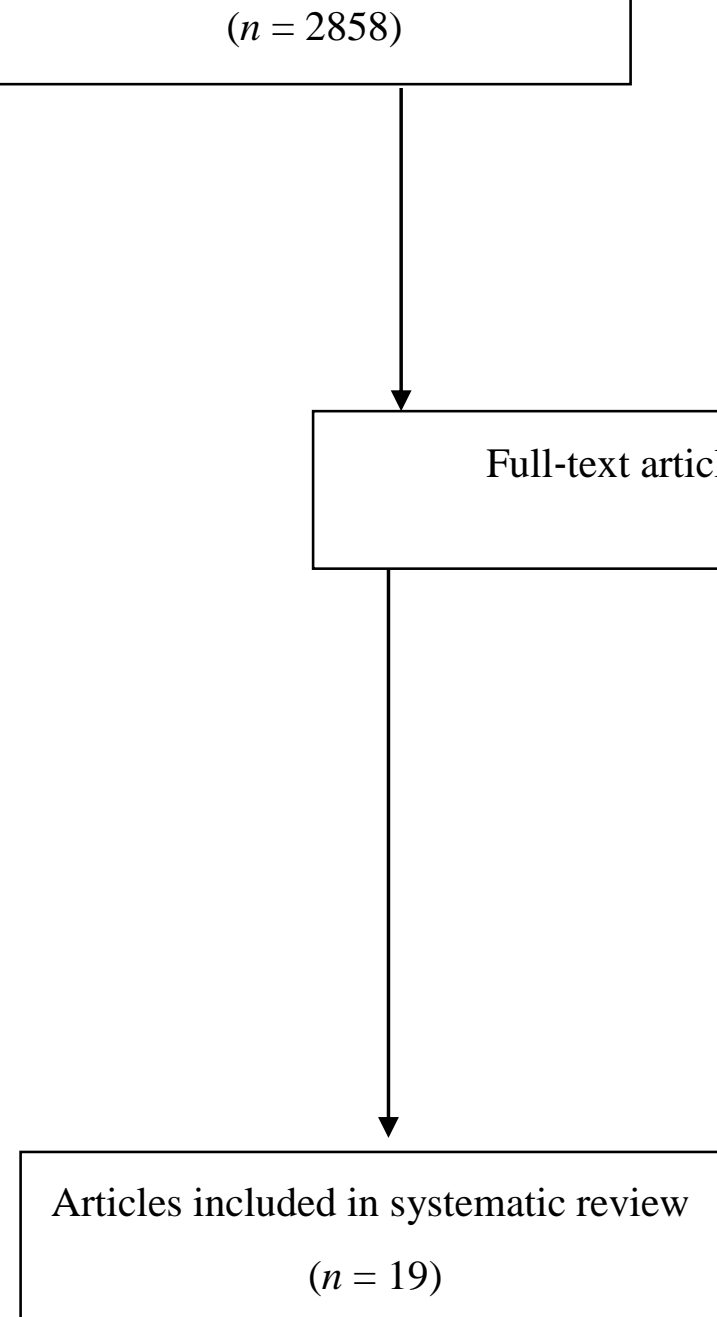

Excluded from review $(n=305)$ 


\section{Sample characteristics}

Participants were predominately male. Thirteen studies included children and young adults $(<21$ years), and in six studies participants were adolescents and adults (age 16 years and above).

\section{Geographical location}

Six studies were from the United States (USA). The remainder were from: the United Kingdom (UK) (4), Australia (2), Sweden (2), Turkey (1), Finland (1), the Netherlands (1); one study included data from both France and the UK; and one from both the USA and Canada.

\section{Design}

All studies were cross-sectional or case control apart from four prospective studies (Cederlund et al 2010; Gillberg et al 2015; Mukkades \& Fateh 2010; Mattila et al 2010) and two using retrospective design (Gadow et al, 2005; Russell et al, 2015). Participants were recruited from clinical settings (11 studies), ASD support or community groups (4 studies) and mixed community/ clinical settings (4).

\section{Study topics of investigation}

The focus of the studies included: examining psychiatric comorbidity (12 studies), psychosocial function (4), self and informant report (2) and profiles of depression (1). Table 3 around here

\section{Risk of bias within studies}

The difference in design between studies that may have contributed to variations in reported rates of depression, are shown in Table 4 and include the following: the majority of studies recruited small numbers of participants (all fewer than 71), with the exception of Russell et al. (2015) ( $n=474)$, Salazar et al. (2015) $(n=101)$, and Gadow et al. (2005) $(n=$ 284). A diagnosis of HF ASD was confirmed during the majority of studies, and so risk of 
177 bias relating to this was low. Twelve studies had some missing detail regarding participants'

178 characteristics (e.g. ethnicity, use of medication), and four studies had missing detail on the

179 recruitment setting (which could have been useful to support generalisability). In four studies

180 IQ was not measured contemporaneously or was not reported (e.g. with participants described 181 as 'high functioning').

Three studies (Bitsika \& Sharpley, 2015; Gadow et al, 2005; Mazefsy et al, 2011) used measures that have some psychometric evidence for their use with people with ASD, including the Autism Comorbidity Interview-Present and Lifetime Version (ACI-PL: Leyfer et al., 2006), the Child and Adolescent Symptom Inventory (CASI: Gadow \& Sprafkin, 2010), and the Child Symptom Inventory-4 (CSI-4: Gadow \& Sprafkin, 2002). These are generic measures with a depression subscale. Otherwise, studies used measures of depression psychometrically validated in the general population, where evidence of psychometric properties in ASD populations was limited or missing.

Table 4 around here

\section{Measures of depression used}

In addition to diagnosis according to ICD-10 criteria the following measures of depression were used.

\section{Informant report and diagnostic interview}

\section{Structured Clinical Interview for DSM-IV (SCID) and Structured Clinical}

Interview for DSM-IV Childhood Disorders (Kid-SCID). The SCID (Spitzer et al, 1992) and

Kid-SCID (Hien et al, 1994) are established diagnostic interviews administered to an individual or child and their parent or carer. Based on DSM-IV criteria their purpose is to help clinicians make a psychiatric diagnosis across a range of conditions including depression. 
Present and Lifetime Version (KSADS-PL). The KSADS-PL (Kaufman et al., 1997) is a psychometrically established semi-structured clinical interview for children. Developed from DSM-IV, its purpose is diagnosis of current or lifetime psychiatric disorders, via child or parent report.

Isle of Wight semi structured interview (IOW). The IOW (Institute of Psychiatry) is a subject and informant psychiatric interview exploring functioning and behaviour.

Children's Interview for Psychiatric Symptoms (P-ChIPS). The P-ChIPS (Weller,

Weller, Teare \& Fristad, 1999) is a one-hour structured psychiatric interview for parents, and which has some psychometric evidence for children with ASD (Witwer, Lecavalier \& Norris, 2012).

Child Symptom Inventory-4 (CSI-4). The CSI-4 (Gadow \& Sprafkin, 2002) is a standardized screening measure which includes a MDD subscale. There are 97 items in the parent, and 77 in the teacher versions. Items are informant rated for frequency and severity of difficulties, and there is evidence of psychometric properties in ASD groups (Gadow, DeVincent \& Schneider, 2008). 2004) is a DSM-IV based semi-structured diagnostic interview for parents of toddlers. Interviews are conducted with parents who are asked about symptoms of disorders, including MDD during the last 3 months. Autism Comorbidity Interview-present and Lifetime (ACI-PL). The ACI-PL (Lainhart et al., 2003) is a semi-structured psychiatric interview about symptoms in the last 3 months, or ever. It was developed from DSM-IV-TR with some evidence of psychometric properties in children with ASD demonstrated (Leyfer et al., 2006). 
Mini International Neuropsychiatric Interview (MINI). The MINI (Sheehan et al. 1998) is a short structured psychiatric diagnostic interview for clinical and research purposes based on DSM 1V and ICD 10.

\section{Self-report measures}

Child and Adolescent Symptom Inventory-4 (CASI-4). The CASI-4 (Gadow \& Sprafkin, 2010) is a standardised self-report measure corresponding to DSM, in which items are rated 0 (never) to 3 (very often). It has a 10 item MDD subscale. The psychometric properties of the CASI-4 have been explored in children with ASD and found to be good, and ASD norms been published.

Patient Health Questionnaire for Adolescents (PHQ-A). The PHQ-A (Johnson, Harris, Spitzer, \& Williams, 2002) is a self-report screening measure with a 15 item MDD section.

Beck Depression Inventory (BDI). The BDI (Beck \& Steer, 1996) is a 21 item selfreport screening measure of depression symptoms during the previous week. The BDI is standardised, has been used in prevalence studies (Cederlund et al., 2010), and scoring thresholds are as follows: $\leq 10$ no depression; 11-14 dysphoria; 15-19 dysphoria/depression; $\geq 20$-28 moderate depression; and $\geq 29$ severe depression.

Child Depression Inventory (CDI). The CDI (Kovacs, 1992) is a standardised screening measure of depression symptoms, with 3 response options across 27 items scores of $\geq 19$ suggest clinical depression.

Hospital Anxiety and Depression Scale (HADS). The HADS (Snaith \& Zigmond, 1994) is a widely used 14 item self-report measure of mood symptoms for medical settings, with much accumulated psychometric evidence.

The measures of depression in the studies reviewed were appropriately used given the ages of study participants. However, the measures developed for the general population could 
250 have introduced some bias, possibly affecting accuracy of reported rates of depression. For example, although the Beck and Child Depression Inventories (BDI and CDI), the SCID, the HADS and the KSADS, have an established evidence base for their psychometric properties in the general population, reliability and validity are not established for individuals with HF ASD. The CSI, the ACI-PL and the CASI-4, do have evidence of reliability and validity in individuals with ASD. However these measures are not depression specific, but rather have a depression subscale, limiting the amount of clinical detail that can be gathered on depression symptoms.

\section{Study Findings: rates of depression}

\section{Informant report}

Informant report current rates of MDD in children are shown in Table 5. Rates of

MDD using generic mental health measures with a depression subscale were between $2.5 \%$ and 29\%. Rates of MDD calculated using measures with psychometric evidence for ASD groups were lower: including $15.8 \%$ on the Autism Co-morbidity Interview (Mazefsky et al., 2011), and between 0\% and 6.2\% on the Child Symptom Inventory (Gadow et al., 2005).

Self-reported rates of depression are shown in Table 6. MDD was 47.1\% measured on the CASI, a generic child measure with a depression subscale (Bitsika \& Sharpley, 2015). Rates were lower using depression specific screening measures. $29 \%$ of children scored above the suggested clinical cut off on the Child Depression Inventory (Vickerstaff et al, 2007), while $35 \%$ of adults self-reported rates of depression above the clinical cut point on the Beck Depression Inventory (Crane et al, 2011). However, only 1\% of adults scored within the severe range (scoring $\geq 30$ on the BDI) (Cederlund et al, 2010), and when the Beck 
Tables 5 and 6 around here

\section{Discussion}

\section{Rates of depression identified}

Rates of depression in people with HF ASD varied widely across studies, from $1 \%$ to 47.1\%. Most rates for people with HF ASD were higher than the general population prevalence rates of $2.5 \%$ to $10.7 \%$ (NSDUH, 2013; Spiers et al, 2012). However, confidence in the validity of comparing these rates of MDD in people with HF ASD to general population prevalence rates, is compromised by a number of factors related to methodological aspects of the studies.

\section{Methodological aspects of the studies}

Only three studies in the review used measures with some psychometric validity for people with HF ASD (the ACI-PL, CSI and the CASI). There is therefore increased confidence in the validity of their reported rates of MDD from studies using these measures (between 15.8\% and 47\%) (Bitsika \& Sharpley, 2015; Mazefsky et al., 2011). Nevertheless, these measures are not depression specific, but rather are generic with a depression subscale. This may influence reported rates for example, the generic Child Behaviour Checklist (CBCL) has some limitations in case recognition, and rates of depression do vary depending on the assessment measures used (Gjevik et al., 2015; Reijnders, Ehrt, Weber, Aarsland \& Leentjens et al., 2008). The remaining studies measured depression using assessments and severity thresholds based on general population norms, which are not necessarily valid for people with HF ASD (Magnuson \& Constantino, 2011). Measures of depression developed for the general population may not accurately capture the presentation of depression in $\mathrm{HF}$ ASD, and evidence of psychometric properties with people with ASD was often not available (Stewart et al., 2006). 
The seemingly high rates of depression in some of the studies reviewed may also result from the relatively small number of participants and select samples used. This is in contrast to the large scale, and demographically representative epidemiological studies on which general population prevalence rates of depression are based. Where studies recruit participants from clinical services (as the studies reviewed predominately did), levels of coexisting conditions are expected to be higher compared to those from community settings (Reijnders et al., 2008). Similarly, medication and comorbidities including physical conditions are confounders with the potential to affect reported rates of depression, but were not always described in studies.

\section{Clinical Implications}

Knowledge of the rates of depression in people with HF ASD facilitates clinicians, managers and commissioners planning services and allocating resources appropriately. UK

National Institute for Health and Care Excellence (NICE) (2009) guidance advocates the use of validated measures for assessment and evaluation of depression interventions. This is currently difficult to implement for people with HF ASD, given the lack of measures of depression psychometrically validated for this group. This may mean clinicians find case recognition and proving treatment effectiveness difficult (Geurts, Stek \& Comijs, 2016; Rosbrook \& Whittingham, 2010). Further work developing a conceptualisation of depression specifically in relation to people with ASD, would facilitate deeper understanding of specific difficulties and the tailoring of treatment interventions for best support.

\section{Strengths and limitations of the review}

We think this is the first systematic review to investigate rates of depression in people with HF ASD. The review adds to existing knowledge by highlighting issues which may influence the magnitude of reported rates in research and clinical settings. 
ASD and ID often co-exist, and it is debated whether depression may be relatively high in people with ID, due to social circumstances and being less responsive to treatment (APA, 2013; Cooper, Smiley, Morrison, Williamson \& Allan, 2007; Jahoda et al., 2015; Tsakanikos et al., 2006). Therefore one limitation of the review is that studies reporting rates of depression in people with ID were excluded, so the findings will not necessarily generalize to individuals with ASD and ID.

For this review the risk of bias was assessed using a measure that was adapted from validated tools. This adaptation may have compromised the reliability and validity of bias assessments.

\section{Recommendations for Future Research}

Prevalence studies of depression across national population samples of people with ASD are a future research priority. Systematic epidemiological surveys of individuals with ASD are rare, but feasible given a large and representative enough sample. For example, Brugha et al., (2011) examined the prevalence of ASD across a sample of 7461 community adults, though information about mental health conditions were not available, and it would be ideal to include a measure of depression in a such a future study. Autism research registry databases are more able to yield population estimates of depression than small clinical samples, or those derived from one geographical area (Baird et al., 2006; Brugha et al., 2011). Fewer adult studies were found reflecting the need for research beyond childhood (Magiati, Tay \& Howlin, 2014). Consideration of the confounding effects of any medication would be important in future studies.

Consolidation of findings to date on phenomenology and correlates of depression in people with HF ASD, would inform development of reliable and valid depression diagnostic and screening measures. Studies have found particular items on the BDI endorsed in ASD groups e.g. guilt, though some general population indicators may be less useful, for example 
asking about social withdrawal given the overlap with ASD characteristics (Gotham, Unruh \& Lord, 2014; Stewart et al, 2006). Further exploration of the relationship between depression and cognitive style e.g. a bias towards internal attributions, or less positive appraisal would inform such developments (Barnhill \& Myles, 2001; Happe \& Frith, 2006). Further exploration of the interaction between depression, core ASD characteristics and IQ, would facilitate case recognition and treatment planning in people with ID and ASD.

In conclusion, rates of depression identified in studies reviewed varied widely. However, the rates should be interpreted cautiously given studies mainly recruited from clinical groups, had small numbers of participants and, given the limited choice of measures psychometrically validated for people with ASD, mainly used measures of depression developed for typically developing groups. Epidemiological studies of depression in ASD could inform service providers and influence decisions on resource allocation. Measures of depression psychometrically validated for people with ASD would be important for these studies, along with accurate case recognition and evaluation of treatment interventions.

The authors have no conflicts of interest to declare.

\section{Acknowledgements}

We are grateful to Northumberland Tyne and Wear NHS Foundation Trust for funding this systematic review. We are also grateful to the UK autism research charity Autistica for funding Sarah Wigham's current post.

\section{References}

Baird, G., Simonoff, E., Pickles, A., Chandler, S., Loucas, T., Meldrum, D., \& Charman, T. (2006). Prevalence of disorder of the autism spectrum in a population cohort of children in South Thames: the Special Needs and Autism Project (SNAP). The Lancet, 368(9531),210-5. 
Barnhill, G.P., \& Myles, B.S. (2001). Attributional style and depression in adolescents with Asperger syndrome. Journal of Positive Behavior Interventions, 3(3), 175-82.

Beck, A., \& Steer, R. (1996). Beck depression inventory [Manual, Swedish version]. Stockholm: Psykologifo“" rlaget.

Bitsika, V., \& Sharpley, C.F. (2015). Differences in the prevalence, severity and symptom profiles of depression in boys and adolescents with an autism spectrum disorder versus normally developing controls. International Journal of Disability, Development and Education, 62(2),158-67.

Brugha, T.S., McManus, S., Bankart, J., Scott, F., Purdon, S., Smith, J., Bebbington, P., Jenkins, R., \& Meltzer, H. (2011). Epidemiology of autism spectrum disorder in adults in the community in England. Archives of general psychiatry, 68(5),459-65.

Cederlund, M., Hagberg, B., \& Gillberg, C. (2010). Asperger syndrome in adolescent and young adult males. Interview, self-and parent assessment of social, emotional, and cognitive problems. Research in developmental disabilities, 31(2),287-98.

Cooper, S. A., Smiley, E., Morrison, J., Williamson, A., \& Allan, L. (2007). An epidemiological investigation of affective disorders with a population-based cohort of 1023 adults with intellectual disabilities. Psychological Medicine, 37(06), 873-882.

Crane, L., Goddard, L., \& Pring, L. (2011). Autobiographical memory in adults with autism spectrum disorder: The role of depressed mood, rumination, working memory and theory of mind. Autism, 17(2),205-19.

Diagnostic and statistical manual of mental disorders: DSM-5 (2013). Washington, D.C: American Psychiatric Association.

Egger, H. L., \& Angold, A. (2004). The preschool age psychiatric assessment (PAPA): A structured parent interview for diagnosing psychiatric disorders in preschool children. Handbook of Infant, Toddler, and Preschool Mental Health Assessment, 223-243.

Gadow, K., \& Sprafkin, J. (2002). Child Symptom Inventory-4 Screening and Norms Manual. Stony Brook, NY: Checkmate Plus.

Gadow, K., Sprafkin, J., Carlson, G., Schneider, J. A., Nolan, E., Mattison, R., \& Rundberg-Rivera, V. (2002). A DSM-IV-referenced adolescent self-reporting scale. Journal of the American Academy of Child and Adolescent Psychiatry, 41 (6), 671-679.

Gadow, K.D., DeVincent, C.J., Pomeroy, J., \& Azizian, A. (2005). Comparison of DSMIV symptoms in elementary school-age children with PDD versus clinic and community samples. Autism, 9(4), 392-415.

Gadow, K. D., DeVincent, C., \& Schneider, J. (2008). Predictors of psychiatric symptoms in children with an autism spectrum disorder. Journal of autism and developmental Disorders, 38(9), 1710-1720.

Gadow, K., \& Sprafkin, J. (2010). Child and adolescent symptom inventory 4R: Screening and norms manual. Stony Brook, NY: Checkmate Plus.

Geurts, H.M., Stek, M., \& Comijs, H. (2016). Autism Characteristics in Older Adults with Depressive Disorder. The American Journal of Geriatric Psychiatry, 24(2), 161-9.

Gillberg, C., \& Billstedt, E. (2000). Autism and Asperger syndrome: coexistence with other clinical disorders. Acta Psychiatrica Scandinavica, 102(5), 321-330.

Gillberg, I.C., Helles, A., Billstedt, E., \& Gillberg, C. (2015). Boys with Asperger Syndrome Grow Up: Psychiatric and Neurodevelopmental Disorder 20 Years After Initial Diagnosis. Journal of autism and developmental disorder, 46(1),7482. 
Gjevik, E., Sandstad, B., Andreassen, O.A., Myhre, A.M., \& Sponheim, E. (2015). Exploring the agreement between questionnaire information and DSM-IV diagnoses of comorbid psychopathology in children with autism spectrum disorder. Autism, 19(4), 433-42.

Gotham, K., Unruh, K., \& Lord, C. (2014). Depression and its measurement in verbal adolescents and adults with autism spectrum disorder. Autism, 19(4), 491-504.

Green, J., Gilchrist, A., Burton, D., \& Cox, A. (2000). Social and psychiatric functioning in adolescents with Asperger syndrome compared with conduct disorder. Journal of autism and developmental disorder, 30(4), 279-93.

Happé, F., \& Frith, U. (2006). The weak coherence account: Detail-focused cognitive style in autism spectrum disorder. Journal of autism and developmental disorder, 36(1), 5-25.

Hien, D., Matzner, F.J., First, M.B., Sptizer, R.L., Gibbon, M., \& Williams, J.B.W. (1994). Structured clinical interview for DSM-IV-child edition (version 1.0). Columbia University: New York.

Hepburn, S.L., Stern, J.A., Blakeley-Smith, A., Kimel, L.K., \& Reaven, J.A. (2014). Complex psychiatric comorbidity of treatment-seeking youth with autism spectrum disorder and anxiety symptoms. Journal of mental health research in intellectual disabilities, 7(4), 359-78.

Hermans, H., \& Evenhuis, H.M. (2010). Characteristics of instruments screening for depression in adults with intellectual disabilities: Systematic review. Research in Developmental Disabilities, 31(6), 1109-20.

Higgins, J.P.T., \& Green, S. (editors). Cochrane Handbook for Systematic Reviews of Interventions Version 5.1.0 [updated March 2011]. The Cochrane Collaboration, 2011. Available from http://handbook.cochrane.org.

Hill, E., Berthoz, S. \& Frith, U. (2004). Brief report: Cognitive processing of own emotions in individuals with autistic spectrum disorder and in their relatives. Journal of autism and developmental disorder, 34(2), 229-35.

Hoy, D., Brooks, P., Woolf, A., Blyth, F., March, L., Bain, C., Baker, P., Smith, E., \& Buchbinder, R. (2012). Assessing risk of bias in prevalence studies: modification of an existing tool and evidence of interrater agreement. Journal of clinical epidemiology, 65(9), 934-9.

De-la-Iglesia, M., \& Olivar, J.S. (2015). Risk Factors for Depression in Children and Adolescents with High Functioning Autism Spectrum Disorder. The Scientific World Journal. Article ID 127853, 17 pagesdoi:10.1155/2015/127853

Jahoda, A., Melville, C. A., Pert, C., Cooper, S. A., Lynn, H., Williams, C., \& Davidson, C. (2015). A feasibility study of behavioural activation for depressive symptoms in adults with intellectual disabilities. Journal of Intellectual Disability Research, 59(11), 1010-1021.

Joanna Briggs Institute. (2014). Joanna Briggs Institute reviewers' manual: the systematic review of prevalence and incidence data 2014 edn. Adelaide, Australia: JBI.

Johansson, R., Carlbring, P., Heedman, Å., Paxling, B., \& Andersson G. (2013). Depression, anxiety and their comorbidity in the Swedish general population: point prevalence and the effect on health-related quality of life. PeerJ. 9(1), e98.

Johnson, J. G., Harris, E. S., Spitzer, R. L., \& Williams, J. B. (2002). The patient health questionnaire for adolescents. Journal of Adolescent Health, 30, 196-204.

Joshi, G., Wozniak, J. Petty, C., Martelon, M.K., Fried, R., Bolfek, A., Kotte, A., Stevens, J., Furtak, S.L., Bourgeois, M., \& Caruso, J. (2013). Psychiatric comorbidity and 
functioning in a clinically referred population of adults with autism spectrum disorders: a comparative study. Journal of Autism and Developmental Disorders, 43(6), 1314-25.

Kaufman, J., Birmaher, B., Brent, D., Rao, U., Flynn, C., Moreci, P., et al. (1997). Schedule for Affective Disorders and Schizophrenia for School-Age ChildrenPresent and Lifetime Version (K-SADS-PL): Initial reliability and validity data. Journal of the American Academy of Child and Adolescent Psychiatry, 36, 980988.

Kelly, A.B., Garnett, M.S., Attwood, T. \& Peterson, C. (2008). Autism spectrum symptomatology in children: The impact of family and peer relationships. Journal of abnormal child psychology, 36(7):1069-81.

Kessler, R.C., Chiu, W.T., Demler, O., \& Walters, E.E. (2005). Prevalence, severity, and comorbidity of 12-month DSM-IV disorder in the National Comorbidity Survey Replication. Archives of general psychiatry, 62(6), 617-27.

Kovacs, M. (1992). Children's depression inventory. New York: Multi-Health Systems.

Lainhart, J. E., Leyfer, O. T., \& Folstein, S. E. (2003). Autism Comorbidity InterviewPresent and Lifetime version (ACI-PL). Salt Lake City: University of Utah.

Leyfer, O.T., Folstein, S.E., Bacalman, S., Davis, N.O., Dinh, E., Morgan, J., TagerFlusberg, H., \& Lainhart, J.E. (2006). Comorbid psychiatric disorder in children with autism: Interview development and rates of disorder. Journal of autism and developmental disorder, 36(7), 849-61.

Magiati, I., Tay, X. W., \& Howlin, P. (2014). Cognitive, language, social and behavioural outcomes in adults with autism spectrum disorders: a systematic review of longitudinal follow-up studies in adulthood. Clinical psychology review, 34(1), 73-86.

Magnuson, K.M., \& Constantino, J.N. (2011). Characterization of depression in children with autism spectrum disorder. Journal of developmental and behavioral pediatrics, 32(4), 332.

Mannion, A., \& Leader, G. (2013). Comorbidity in autism spectrum disorder: A literature review. Research in autism spectrum disorder, 7(12), 1595-616.

Matson, J.L., \& Nebel-Schwalm, M.S. (2007). Comorbid psychopathology with autism spectrum disorder in children: An overview. Research in developmental disabilities, 28(4), 341-52.

Mattila, M.L., Hurtig, T., Haapsamo, H., Jussila, K., Kuusikko-Gauffin, S., Kielinen, M., Linna, S.L., Ebeling, H., Bloigu, R., Joskitt, L., \& Pauls, D.L. (2010). Comorbid psychiatric disorder associated with Asperger syndrome/high-functioning autism: A community-and clinic-based study. Journal of autism and developmental disorder, 40(9), 1080-93.

Mazefsky, C.A., Kao, J., \& Oswald, D.P. (2011). Preliminary evidence suggesting caution in the use of psychiatric self-report measures with adolescents with highfunctioning autism spectrum disorder. Research in Autism Spectrum Disorder, $5(1), 164-74$.

Mazurek, M.O., \& Kanne, S.M. (2010). Friendship and internalizing symptoms among children and adolescents with HF ASD. Journal of autism and developmental disorder, 40(12), 1512-20.

Mazzone, L., Ruta, L., \& Reale, L. (2012). Psychiatric comorbidities in asperger syndrome and high functioning autism: diagnostic challenges. Ann Gen Psychiatry, 11(1), 1 . 
Mukaddes, N.M., \& Fateh, R.(2010). High rates of psychiatric co-morbidity in individuals with Asperger's disorder. The World Journal of Biological Psychiatry, 11(2-2), 486-92.

Munn, Z., Moola, S., Riitano, D., \& Lisy, K. (2014). The Development of a Critical Appraisal Tool for Use in Systematic Reviews: Addressing Questions of Prevalence. International Journal of Health Policy \& Management, 13 (3), 123.

NICE (2009) Depression: the Treatment and Management of Depression in Adults (Update). NICE clinical guideline 90. Available at www.nice.org.uk/CG90 [NICE guideline].

NSDUH (2013). Substance Abuse and Mental Health Services Administration, Results from the 2013 National Survey on Drug Use and Health: Mental Health Findings, NSDUH Series H-49, HHS Publication No. (SMA) 14-4887. Rockville, MD: Substance Abuse and Mental Health Services Administration, 2014.

Orinstein, A., Tyson, K.E., Suh, J., Troyb, E., Helt, M., Rosenthal, M., Barton, M.L., Eigsti, I.M., Kelley, E., Naigles, L., \& Schultz, R.T. (2015). Psychiatric Symptoms in Youth with a History of Autism and Optimal Outcome. Journal of autism and developmental disorder, 45(11), 3703-14.

Reijnders, J.S., Ehrt, U., Weber, W.E., Aarsland, D. \& Leentjens, A.F. (2008). A systematic review of prevalence studies of depression in Parkinson's disease. Movement Disorder, 23(2), 183-9.

Rosbrook, A., \& Whittingham, K (2010). Autistic traits in the general population: What mediates the link with depressive and anxious symptomatology? Research in Autism Spectrum Disorder, 4(3), 415-24.

Russell, A.J., Murphy, C.M., Wilson, E. Gillan, N., Brown, C., Robertson, D.M., Craig, M.C., Deeley, Q., Zinkstok, J., Johnston, K., McAlonan, G.M., Spain, D., \& Murphy, D. (2015). The mental health of individuals referred for assessment of autism spectrum disorder in adulthood: A clinic report. Autism, 20(5), 623-7.

Salazar, F., Baird, G., Chandler, S., Tseng, E., O’Sullivan, T., Howlin, P., Pickles, A., \& Simonoff, E. (2015). Co-occurring psychiatric disorder in preschool and elementary school-aged children with Autism Spectrum Disorder. Journal of autism and developmental disorder, 45(8), 2283-94.

Sheehan, D. V., Lecrubier, Y., Sheehan, K. H., Amorim, P., Janavs, J., Weiller, E., et al. (1998). The mini-international neuropsychiatric interview (M.I.N.I.): The development and validation of a structured diagnostic psychiatric interview for DSM-IV and ICD-10. Journal of Clinical Psychiatry, 59(20), 22-33.

Shtayermman, O. (2008). Suicidal ideation and comorbid disorder in adolescents and young adults diagnosed with Asperger's syndrome: A population at risk. Journal of Human Behavior in the Social Environment, 18(3), 301-28.

Skokauskas, N. \& Gallagher, L. (2009). Psychosis, affective disorder and anxiety in autistic spectrum disorder: prevalence and nosological considerations. Psychopathology, 43(1), 8-16.

Snaith, R.P. \& Zigmond, A.S. HADS: Hospital Anxiety and Depression Scale. Windsor: NFER Nelson 1994.

Spiers, N., Brugha, T.S., Bebbington, P., McManus, S., Jenkins, R., \& Meltzer, H. (2012). Age and birth cohort differences in depression in repeated cross-sectional surveys in England: the National Psychiatric Morbidity Surveys, 1993 to 2007. Psychological medicine, 42(10), 2047-55. 
Spitzer, R. L., Williams, J. B., Gibbon, M., \& First, M. B. (1992). The structured clinical interview for DSM-III-R (SCID): I: history, rationale, and description. Archives of general psychiatry, 49(8), 624-629.

Sterling, L., Dawson, G., Estes, A., \& Greenson, J. (2008). Characteristics associated with presence of depressive symptoms in adults with autism spectrum disorder. Journal of autism and developmental disorder, 38(6), 1011-8.

Stewart, M.E., Barnard, L., Pearson, J., Hasan, R., \& O’Brien, G. (2006). Presentation of depression in autism and Asperger syndrome A review. Autism, 10(1),103-16.

Strang, J.F., Kenworthy, L., Daniolos, P., Case, L., Wills, M.C., Martin, A., \& Wallace, G.L. (2012). Depression and anxiety symptoms in children and adolescents with autism spectrum disorder without intellectual disability. Research in Autism Spectrum Disorder, 6(1), 406-12.

Tsai, L.Y. (2014). Prevalence of Comorbid Psychiatric Disorder in Children and Adolescents with Autism Spectrum Disorder. Journal of Experimental \& Clinical Medicine, 6(6), 179-86.

Tsakanikos, E., Costello, H., Holt, G., Bouras, N., Sturmey, P., \& Newton, T. (2006). Psychopathology in adults with autism and intellectual disability. Journal of Autism and Developmental Disorders, 36(8), 1123-1129.

van Steensel, F.J., Bögels, S.M., \& de Bruin, E.I. (2013). Psychiatric comorbidity in children with autism spectrum disorder: A comparison with children with ADHD. Journal of Child and Family Studies, 22(3), 368-76.

Vickerstaff, S., Heriot, S., Wong, M., Lopes, A., \& Dossetor, D. (2007). Intellectual ability, self-perceived social competence, and depressive symptomatology in children with high-functioning autistic spectrum disorder. Journal of autism and developmental disorder, 37(9),1647-64.

Weller, E. B., Weller, R. A., Teare, M., \& Fristad, M. A. (1999). Parent Version Children's Interview for Psychiatric Syndromes (P-ChIPS). Washington: American Psychiatric Press.

Whitehouse, A.J., Durkin, K., Jaquet, E., \& Ziatas, K. (2009). Friendship, loneliness and depression in adolescents with Asperger's Syndrome. Journal of adolescence, 32(2), 309-22.

Williams, S.B., O'Connor, E.A., Eder, M., \& Whitlock, E.P. (2009). Screening for child and adolescent depression in primary care settings: a systematic evidence review for the US Preventive Services Task Force. Pediatrics, 123(4):e716-35.

Witwer, A.N. \& Lecavalier, L. (2010). Validity of comorbid psychiatric disorder in youngsters with autism spectrum disorder. Journal of Developmental and Physical Disabilities, 22(4), 367-80.

Witwer, A. N., Lecavalier, L., \& Norris, M. (2012). Reliability and validity of the Children's interview for psychiatric syndromes-parent version in autism spectrum disorders. Journal of autism and developmental disorders, 42(9),1949-58. 
Table 1. Inclusion and exclusion criteria

\section{Inclusion criteria}

Population Individuals of all ages with HF ASD and without intellectual disability (FSIQ $>/=70$ )

Context Clinical and community

Condition Current major depressive disorder; severe or clinical depression with specified thresholds.

Design Empirical group studies

Measure Specific measures of depression; generic measures with a depression subscale; ICD or DSM

\section{Exclusion criteria}

FSIQ $<70$

None

Non-specific affective disorder; subclinical depression/dysthymia. Lifetime depression. No actual thresholds described in the paper. Case studies, case series, reviews

Studies measuring presence of depression with one question e.g. 'has anyone ever told you that you have/ your child has depression?' 
Table 2. Bias rating chart for studies selected for the review

\section{Diagnosis of HF ASD}

1. A diagnosis of HF ASD was made prior to the study - no details given on method; or a different test used to those listed below (see 3)

2. Individuals were recruited from an HF ASD research database. A diagnosis of HF ASD was made prior to the study using the methods below.

3. A diagnosis of HF ASD was confirmed at the time of the study by standardised test including; or by a psychologist or psychiatrist and DSM or ICD.

\section{Assessment of depression}

1. Non standardised

2. Depression subscale within a standardised generic measure

3. Standardised depression specific assessment or clinical interview; or diagnosis of depression according to DSM or ICD by psychiatrist or psychologist

\section{Clear description of participants}

1. Key demographic information missing.

2. Some descriptive characteristics included; or reference to where further details can be found is provided

3. Key characteristics described including: mean age, age range, gender, comorbidity, medication, ethnicity

\section{Description of recruitment pool provided}

1. Recruitment pool is not described.

2. Some detail provided

3. Recruitment pool described including: geographical area, method of referral (e.g. self, database), setting (e.g. clinic or school)

\section{Reliability and validity of depression outcome measure in HF ASD populations}

1. No psychometric properties reported for HF ASD

2. Some evidence of reliability and validity

3. The measure is standardised for HF ASD populations 


\section{Measure of IQ}

\section{None give}

2. IQ given or e.g. described as all being $>70$ or having Asperger

3. IQ measured during study (using e.g. Wechsler Adult Intelligence Scale (WAIS), Wechsler Intelligence Scale for Children (WISC), Stanford-Binet) 
Table 3. Characteristics of included studies

\begin{tabular}{|c|c|c|c|c|c|c|c|}
\hline Author & Country & Population & $\begin{array}{l}\text { ASD N } \\
(\text { male) }\end{array}$ & \begin{tabular}{|l} 
Age (years) \\
Mean (SD); range
\end{tabular} & $\begin{array}{l}\text { Mean FSIQ } \\
\text { (SD); range }\end{array}$ & Medication & $\begin{array}{l}\text { Outcomes related to } \\
\text { depression }\end{array}$ \\
\hline $\begin{array}{l}\text { Green, Gilchrist, Burton \& } \\
\text { Cox (2000) }\end{array}$ & UK & Clinical referrals & $20(20)$ & $13.75(11-19)$ & 92.15 (17.7); 71-141 & $10 \%$ & $\begin{array}{l}\text { Psychosocial } \\
\text { functioning }\end{array}$ \\
\hline $\begin{array}{l}\text { Hill, Berthoz \& Frith } \\
\text { (2004) }\end{array}$ & $\begin{array}{l}\text { France and } \\
\text { UK }\end{array}$ & $\begin{array}{l}\text { Support groups/ } \\
\text { community centres }\end{array}$ & $27(15)$ & $\begin{array}{l}35.07(12.26) \\
16-63\end{array}$ & HF ASD & NR & Emotion processing \\
\hline $\begin{array}{l}\text { Gadow, DeVincent, } \\
\text { Pomeroy \& Azizian } \\
(2005)\end{array}$ & USA & $\begin{array}{l}\text { Developmental disability } \\
\text { clinic }\end{array}$ & $284(242)$ & $8.3(1.8) 6-12$ & $92(22.2)$ & $38 \%$ & Psychiatric comorbidity \\
\hline $\begin{array}{l}\text { Vickerstaff, Heriot, Wong, } \\
\text { Lopes \& Dossetor (2007) }\end{array}$ & Australia & Social skills training & $22(19)$ & $\begin{array}{l}11.86(1.65) \\
7-13\end{array}$ & $\begin{array}{l}\text { 105.41 (15.34); } \\
82-141\end{array}$ & NR & Social skills \\
\hline Shtayermman (2008) & USA & $\begin{array}{l}\text { Autism Websites; } \\
\text { previous research } \\
\text { participants }\end{array}$ & $10(9)$ & $19.7(3)$ & Asperger & $89 \%$ & $\begin{array}{l}\text { Suicidal ideation; } \\
\text { comorbidity }\end{array}$ \\
\hline $\begin{array}{l}\text { Cederlund, Hagberg \& } \\
\text { Gillberg (2010) }\end{array}$ & Sweden & Neuropsychiatric clinic & $71(71)$ & $21.8(4.6) 16-36$ & $103.8(15.2)$ & $18 \%$ & Informant agreement \\
\hline Mattila et al. (2010) & Finland & $\begin{array}{l}\text { Community } \\
\text { \& clinical }\end{array}$ & $50(38)$ & $\begin{array}{l}12.7(1.5) \\
9-16\end{array}$ & $>75$ & NR & Psychiatric comorbidity \\
\hline Mukkades \& Fateh (2010) & Turkey & Psychiatric clinic & $37(32)$ & \begin{tabular}{|l|}
$10.9(4.5)$ \\
$6-20$ \\
\end{tabular} & $116(14) 90-139$ & NR & Psychiatric comorbidity \\
\hline $\begin{array}{l}\text { Witwer \& Lecavalier } \\
\text { (2010) }\end{array}$ & USA & $\begin{array}{l}\text { University and } \\
\text { psychiatry clinics; } \\
\text { previous research } \\
\text { participants, ASD groups }\end{array}$ & $61(50)$ & $\begin{array}{l}11.2(3.8) \\
6-17\end{array}$ & $\begin{array}{l}>70 \\
(n=22)\end{array}$ & $5 \%-61 \%$ & Psychiatric comorbidity \\
\hline $\begin{array}{l}\text { Crane, Goddard \& Pring } \\
\text { (2011) }\end{array}$ & UK & $\begin{array}{l}\text { National Autistic } \\
\text { Society. } \\
\text { Support groups / web } \\
\text { pages }\end{array}$ & $28(14)$ & 41.57 (16.49) & $117.18(13.47)$ & NR & $\begin{array}{l}\text { Autobiographical } \\
\text { memory }\end{array}$ \\
\hline $\begin{array}{l}\text { Mazefsy, Kao \& Oswald } \\
\text { (2011) }\end{array}$ & USA & $\begin{array}{l}\text { Word of mouth /fliers in } \\
\text { developmental disorder } \\
\text { clinic }\end{array}$ & $38(31)$ & $12(2) 10-17$ & $\begin{array}{l}105(17) \\
71-144\end{array}$ & $42 \%$ & Self-report measures \\
\hline
\end{tabular}




\begin{tabular}{|c|c|c|c|c|c|c|c|}
\hline Joshi et al (2013) & USA & ASD clinic & $63(41)$ & $29(11) ; 18-63$ & $\begin{array}{l}104.4(17.3) \\
97 \%>70\end{array}$ & $60 \%$ & Psychiatric comorbidity \\
\hline $\begin{array}{l}\text { van Steensel, Bögels, \& de } \\
\text { Bruin (2013) }\end{array}$ & Netherlands & $\begin{array}{l}\text { Outpatient mental health } \\
\text { centre }\end{array}$ & $40(36)$ & $11.10(2.82) ; 8-18$ & $88 \%>70$ & NR & Psychiatric comorbidity \\
\hline $\begin{array}{l}\text { Hepburn, Stern, Blakeley- } \\
\text { Smith, Kimel \& Reaven } \\
\text { (2014) }\end{array}$ & USA & $\begin{array}{l}\text { Participants in a CBT } \\
\text { study }\end{array}$ & $42(34)$ & $10.9(1.8) ; 8-14$ & $\begin{array}{l}98.4(15) \\
63-129\end{array}$ & NR & Psychiatric comorbidity \\
\hline Bitsika \& Sharpley (2015) & Australia & $\begin{array}{l}\text { Parent support } \\
\text { group; schools }\end{array}$ & $70(70)$ & $\begin{array}{l}10.9(3.4) \\
8-18\end{array}$ & FSIQ: 96.21 (14.23) & $\begin{array}{l}\text { No anti- } \\
\text { depressants }\end{array}$ & $\begin{array}{l}\text { Prevalence, severity } \\
\text { and symptom profiles }\end{array}$ \\
\hline $\begin{array}{l}\text { Gillberg, Helles, Billstedt } \\
\text { \& Gillberg, (2015) }\end{array}$ & Sweden & Neuropsychiatric clinic & $50(50)$ & $30.2(5.0) ; 23-43$ & FSIQ: 107.6 & NR & $\begin{array}{l}\text { Psychiatric disorders } \\
20 \text { years after ASD } \\
\text { diagnosis }\end{array}$ \\
\hline Orinstein et al. (2015) & $\begin{array}{l}\text { USA and } \\
\text { Canada }\end{array}$ & $\begin{array}{l}\text { Multiple hospital and } \\
\text { university sites }\end{array}$ & $42(38)$ & $13.9(2.7) ; 8-20$ & $\begin{array}{l}\text { VIQ: } 105.5(14.7) \\
81-142\end{array}$ & NR & $\begin{array}{l}\text { Psychiatric } \\
\text { comorbidity }\end{array}$ \\
\hline Russell et al. (2015) & UK & ASD clinic & $474(372)$ & $30.59(11.18)$ & $\begin{array}{l}\text { Excluded those with } \\
\text { suspected ID }\end{array}$ & NR & $\begin{array}{l}\text { Psychiatric } \\
\text { comorbidity }\end{array}$ \\
\hline Salazar et al. (2015) & UK & $\begin{array}{l}\text { Primary care and ASD } \\
\text { support group }\end{array}$ & $101(57)$ & $6.7(1) ; 4-9$ & $>70(n=44)$ & NR & $\begin{array}{l}\text { Psychiatric } \\
\text { comorbidity }\end{array}$ \\
\hline
\end{tabular}

NR: not reported 
Table 4. Bias within studies

\begin{tabular}{|c|c|c|c|c|c|c|}
\hline Article & $\begin{array}{l}\text { Diagnosis of } \\
\text { ASD }\end{array}$ & $\begin{array}{l}\text { Depression } \\
\text { measure }\end{array}$ & $\begin{array}{l}\text { Description of } \\
\text { participants }\end{array}$ & $\begin{array}{l}\text { Description of } \\
\text { recruitment pool }\end{array}$ & $\begin{array}{l}\text { Reliability/ validity of } \\
\text { depression measure in } \\
\text { ASD }\end{array}$ & Measure of IQ \\
\hline \multicolumn{7}{|l|}{ Green et al. (2000) } \\
\hline \multicolumn{7}{|l|}{ Hill et al. (2004) } \\
\hline \multicolumn{7}{|l|}{ Gadow et al. (2005) } \\
\hline \multicolumn{7}{|c|}{ Vickerstaff et al. (2007) } \\
\hline \multicolumn{7}{|l|}{ Shtayermman (2008) } \\
\hline \multicolumn{7}{|l|}{ Cederlund et al. (2010) } \\
\hline \multicolumn{7}{|l|}{ Mattila et al. (2010) } \\
\hline \multicolumn{7}{|c|}{ Mukkades et al. (2010) } \\
\hline \multicolumn{7}{|l|}{ Witwer et al. (2010) } \\
\hline \multicolumn{7}{|l|}{ Crane et al. (2011) } \\
\hline \multicolumn{7}{|l|}{ Mazefsky et al. (2011) } \\
\hline \multicolumn{7}{|l|}{$\begin{array}{l}\text { Joshi et al (2013) } \\
\text { (2013) }\end{array}$} \\
\hline \multicolumn{7}{|c|}{$\begin{array}{l}\text { van Steensel et al. (2013) } \\
\text { (2) }\end{array}$} \\
\hline \multicolumn{7}{|l|}{ Hepburn et al. (2014) } \\
\hline \multicolumn{7}{|l|}{$\begin{array}{l}\text { Bitsika \& Sharpley } \\
(2015)\end{array}$} \\
\hline \multicolumn{7}{|l|}{ Gillberg et al. (2015) } \\
\hline \multicolumn{7}{|l|}{ Orinstein et al. (2015) } \\
\hline \multicolumn{7}{|l|}{ Russell et al. (2015) } \\
\hline Salazar et al. (2015) & & & & & & \\
\hline
\end{tabular}


Table 5. Study findings: diagnostic interview or informant reported current rates of depression and measure used (parent reported unless stated otherwise)

\begin{tabular}{l|l|l|l}
\hline Author & $\begin{array}{l}\text { Age group } \\
\text { Child/Adult (C/A) }\end{array}$ & Rates of major depressive disorder & Measure \\
\hline
\end{tabular}

\section{Generic measures with a depression subscale}

\begin{tabular}{|c|c|c|c|}
\hline Joshi et al (2013) & A & $31 \%$ (self and parent/ guardian report) & Structured Clinical Interview for DSM-IV (SCID) \\
\hline $\begin{array}{l}\text { Van Steensel et al. } \\
\text { (2013) }\end{array}$ & $\mathrm{C}$ & $2.5 \%$ & $\begin{array}{l}\text { Structured Clinical Interview for DSM-IV Childhood } \\
\text { Disorders (KID SCID) }\end{array}$ \\
\hline Mattilla et al. (2010) & $\mathrm{C}$ & $6 \%$ & \multirow{4}{*}{$\begin{array}{l}\text { Schedule for Affective Disorders and Schizophrenia for } \\
\text { School-Age Children-Present and Lifetime Version } \\
\text { (KSADS-PL) }\end{array}$} \\
\hline Mukkades et al. 2010 & $\mathrm{C}$ & $29 \%$ & \\
\hline Hepburn et al. (2014) & $\mathrm{C}$ & $14.3 \%$ & \\
\hline Orinstein et al. (2015) & $\mathrm{C}$ & $7 \%$ & \\
\hline Green et al. (2000) & $\mathrm{C}$ & $5 \%$ & Isle of Wight Semi structured Interview \\
\hline Gadow et al. (2005) & $\mathrm{C}$ & $\begin{array}{l}\text { Parent rated: males }(6.2 \%) \text { females }(2.4 \%) \\
\text { Teacher rated: males }(2.9 \%) \text { females }(0 \%)\end{array}$ & Child Symptom Inventory-4 (CSI-4) \\
\hline Witwer et al. (2010) & $\mathrm{C}$ & $22.7 \%$ & Children's Interview for Psychiatric Symptoms (P-ChIPS) \\
\hline Salazar et al. (2015) & $\mathrm{C}$ & $18.8 \%$ & Preschool Age Psychiatric Assessment (PAPA) \\
\hline \multicolumn{4}{|c|}{ Measures of ASD Co-morbidity } \\
\hline Mazefsky et al. (2011) & $\mathrm{C}$ & $15.8 \%$ & $\begin{array}{l}\text { Autism Comorbidity Interview-present and Lifetime (ACI- } \\
\text { PL) }\end{array}$ \\
\hline
\end{tabular}


Table 6. Study findings: self-reported current rates of depression and measure used

\begin{tabular}{|c|c|c|c|c|}
\hline Author & $\begin{array}{l}\text { Age group Child/Adult } \\
\text { (C/A) }\end{array}$ & Clinical depression & MDD & Measure \\
\hline \multicolumn{5}{|c|}{ Generic measures with a depression subscale } \\
\hline Bitsika \& Sharpley (2015) & $\mathrm{C}$ & & $47.1 \%$ & $\begin{array}{l}\text { Child and Adolescent Symptoms Inventory } \\
\text { (CASI) }\end{array}$ \\
\hline Russell et al (2015) & $\mathrm{A}$ & $15.8 \%$ depressive episode & & $\begin{array}{l}\text { Hospital Anxiety and Depression Scale (and } \\
\text { ICD 10) }\end{array}$ \\
\hline Shtayermman (2008) & $\mathrm{C}$ & & $20 \%$ & Patient Health Questionnaire for Adolescents \\
\hline \multicolumn{3}{|c|}{ Standardised depression specific measures } & & Beck Depression Inventory (BDI) \\
\hline Hill et al. (2004) & $\mathrm{A}$ & $22.2 \%($ scored $>/=20)$ & & \\
\hline Cederlund et al. (2010) & $\mathrm{A}$ & $1 \%$ severe depression $($ scored $=/>30)$ & & \\
\hline Crane et al. (2011) & $\mathrm{A}$ & $35 \%($ scored $>/=20)$ & & \\
\hline Gillberg et al. (2015) & $\mathrm{A}$ & & $4 \%$ & $\begin{array}{l}\text { BDI in combination with Mini International } \\
\text { Neuropsychiatric Interview }\end{array}$ \\
\hline Vickerstaff et al. (2007) & $\mathrm{C}$ & $29 \%($ scored $>/=19)$ & & Child Depression Inventory \\
\hline
\end{tabular}

